\title{
A systematic review of emerging human coronavirus (SARS-CoV-2) outbreak: focus on disinfection methods, environmental survival, and control and prevention strategies
}

\author{
Zahra Noorimotlagh $^{1,2} \cdot$ Seyyed Abbas Mirzaee ${ }^{1,2}$ (1) $\cdot$ Neemat Jaafarzadeh $^{3} \cdot$ Maryam Maleki $^{4} \cdot$ \\ Gholamreza Kalvandi $^{5} \cdot$ Chiman Karami $^{6}$
}

Received: 27 May 2020 / Accepted: 29 September 2020 / Published online: 2 October 2020

(C) Springer-Verlag GmbH Germany, part of Springer Nature 2020

\begin{abstract}
Recently, an outbreak of a novel human coronavirus which is referred to as severe acute respiratory syndrome coronavirus 2 (SARS-CoV-2) (COVID-19) by the World Health Organization (WHO) was identified in Wuhan, China. To help combat the pandemic, a systematic review (SR) was performed to collect all available studies concerning inactivation methods, environmental survival, and control and prevention strategies. A comprehensive literature survey yielded 42 eligible studies which included in the SR. The results confirmed that the WHO recommended two alcohol-based hand rub formulations (ethanol 7095\% and 2-propanol 70-100\%) had an efficient virucidal activity in less than $60 \mathrm{~s}$ by more and equal $4 \log _{10}(\geq 99.99)$ approximately and could be used for disinfection in public health and health-care facilities. The findings indicated that SARSCoV-1 and SARS-CoV-2 can survive under different environmental conditions between 4 and $72 \mathrm{~h}$ approximately. The results also demonstrate that temperature and relative humidity are important factors in the survival of SARS-CoV-2. The main strategies recommended by the WHO to avoid contracting SARS-CoV-2 are hand washing several times in the day and maintaining social distancing with others. It is important to note that the more studies require addressing, the more possible airborne transmission due to the survival of SARS-CoV-2 in aerosols for $3 \mathrm{~h}$ approximately. We hope that the results of the present SR can help researchers, health decision-makers, policy-makers, and people for understanding and taking the proper behavior to control and prevent further spread of SARS-CoV-2.
\end{abstract}

\section{Highlights}

- A SR was performed to collect all available studies on inactivation methods, environmental survival, and control and prevention strategies.

- A comprehensive literature survey yielded 42 eligible studies which included in SR.

- Results show that the WHO recommended two alcohol-based hand rub formulations had an efficient virucidal activity in less than $60 \mathrm{~s}$.

- SARS-CoV-1 and SARS-CoV-2 can survive under different environmental conditions between 4 and $72 \mathrm{~h}$.

- The main strategies recommended by the WHO are hand washing several times in the day and maintaining social distancing with others.

Responsible Editor: Lotfi Aleya

Seyyed Abbas Mirzaee

mirzaee.seyyed@gmail.com

Neemat Jaafarzadeh

Jaafarzadeh-n@ajums.ac.ir; n.jaafarzade@yahoo.com

Zahra Noorimotlagh

noorimotlagh.zahra@gmail.com

Maryam Maleki

maryammaleki777@yahoo.com
Gholamreza Kalvandi

pezeshk1351@yahoo.com

Chiman Karami

chkarami.chiman@gmail.com

Extended author information available on the last page of the article 
Keywords SARS-CoV-2 · COVID-19 · Inactivation methods · Environmental survival · Prevention strategies

\section{Introduction}

Coronaviruses (CoVs) belong to the family of Coronaviridae that includes four genera: alpha coronavirus $(\alpha-\mathrm{CoV})$, beta coronavirus $(\beta-\mathrm{CoV})$, gamma coronavirus $(\gamma-\mathrm{CoV})$, and delta coronavirus $(\delta-\mathrm{CoV})$ (Yin and Wunderink 2018). Alpha- and $\beta$-CoVs can infect mammals, and two others can infect birds as well as mammals. Seven CoVs have been known to infect human so far. Four of them, HCoV-229E, HCoV-OC43, HCoV-NL63, and HCoV-HKU1, lead to the self-limited upper respiratory tract infection (Chang et al. 2020). Middle East respiratory syndrome-coronavirus (MERS-CoV) and severe acute respiratory syndrome coronavirus 1 (SARS-CoV-1) both cause lower respiratory tract infection and lead to severe respiratory syndrome (Ding et al. 2003).

During the last few months, an outbreak of pneumonia with unknown origin and etiology was identified in Wuhan city, the most populous city in central China with a population more than 11 million, at Hubei province on 31 December 2019. It was acknowledged that the outbreak resulted from a novel coronavirus $(\mathrm{CoV})$; first, it was named as the 2019$\mathrm{nCoV} 2$ and recently referred to as severe acute respiratory syndrome coronavirus 2 (SARS-CoV-2), and its related disease is now entitled CoV disease 2019 (COVID-19) by the WHO (Peng et al. 2020; Sohrabi et al. 2020).

During the last two decades, in addition to severe acute respiratory syndrome coronavirus 2 (SARS-CoV-2) (emerged in 2003 in China) and Middle East respiratory syndromeCoronavirus (MERS-CoV) (was first emerged in September 2012 and as of September 2019 in Saudi Arabia), this is the third high pathogenic $\mathrm{HCoV}$ with a pandemic spread and now has a total of 2,626,321 confirmed cases with pneumonia and 181,938 deaths worldwide (as of April 24, 2020) ((WHO), 2020b, Al-Rabiaah et al. 2020).

This virus has several properties that make it difficult to deal with these properties including non-particular aspects of the disease, long incubation period, infectivity even before symptoms appearing in the incubation duration, contagious nature of this virus infection even in asymptomatic infected people, and extended disease period and transmission. More so, recovery might start about the 2 nd or 3 rd week following infection (Singhal 2020). On 30 January 2020, responding to the rapid growth of this viral outbreak and confirmed humanto-human contagion, the WHO stated a public health emergency of international concern (Peng et al. 2020).

As there is no approved treatment for this viral infection, prevention is essential (Singhal 2020; Smatti et al. 2018). The environment conditions play an important role in the spread of the infectious virus; also, the control of virus infections is an issue of major concern and a great challenge. Introducing optimized disinfection methods is vital to prevent and minimize the infection spread (Abreu et al. 2013). Through recent decades, requirements as to the antimicrobial activities of disinfectants in the medical setting have been appointed based on various criterions. In addition, guidelines have been prepared to recommend people and hospitals to fully clear and disinfect environmental and medical instrument surfaces on a regular basis (Pitten et al. 2003; Carling et al. 2008). In the current SARS-CoV-2 pandemic, identification of the chemical and/or physical disinfectant that interrupts the virus transmission routes including human-to-human, spreads via respiratory droplets, and contaminated hands or surfaces are of utmost importance. Therefore, the present SR attempts to provide sufficient information and strategies for viral inactivation (disinfection) methods and determine the virus survival in different environmental conditions and control and prevention strategies.

\section{Methods}

A comprehensive search was conducted on all the available papers from literature reporting on disinfection (inactivation), environmental survival, and control and prevention strategies with a focus on $\mathrm{HCoV}$. We followed the Cochrane Reviewer's Handbook and PRISMA (Preferred Reporting Items for SR and Meta-analysis) guidelines for writing of the protocol of the present SR (http://www.prisma-statement.org/Extensions/ InDevelopment.aspx) (Mohamoud et al. 2013; Noorimotlagh et al. 2020).

\section{Information sources and search strategy}

To identify different disinfectants and environmental survival associated with $\mathrm{HCoV}$ as well as control and prevention methods of this novel virus, a comprehensive search was systematically carried out between 1990 and 2020. The last systematic search was conducted on April 24, 2020. Main database of the Elsevier Bibliographic Database (Scopus), Institute for Scientific Information (ISI) Web Science, Google Scholar, PubMed (MEDLINE), World Health Organization (WHO, https://www.who.int/), and American Centers for Disease Control and Prevention (CDC, https:// www.cdc.gov/) were used to search using free text words, MeSH (Medical Subject Headings), and their possible combination. Therefore, we searched in aforementioned databases with proper keywords: "Coronaviruses" OR "CoV" OR "Human Coronaviruses " OR "HCoV" OR "nCov" OR "Novel Coronaviruses " OR "2019 Novel Coronavirus" OR "Covid-19” OR "2019-nCoV” OR “ 
Severe Acute Respiratory Syndrome- Coronaviruses-2" OR "SARS-COV-2") AND ("Disinfectant" OR "Disinfection" OR "Chemical Inactivation" OR "Physical Inactivation" OR "Germicide Susceptibility") AND ("Environmental Resistance" OR "Environmental Stability" OR "Environmental Persistence" OR "Inanimate surfaces" OR "Persistence Skin" OR "Persistence Surface" OR "Persistence Hand" OR "Survival Skin" OR "Survival Hand") AND ("Prevention Methods" OR "Infection Prevention and Control" OR "Environmental Survival"), as illustrated in Fig. 1.

\section{Included/excluded criteria for reviewed studies}

This study was systematically considered and collated articles into the following: (a) original articles, (b) studies published in English, (c) available electronic version (online), and (e) articles focusing on disinfections, environmental survival, and control and prevention strategies of $\mathrm{HCoV}$. The excluded criteria for this SR were review articles, book review, guidelines, book chapters, duplicate articles, short communications, conference documents, oral presentation, and comments.

\section{Data extraction}

In the present work, M.SA and ZN systematically investigated title-abstract and full text to avoid bias. Then, information such as first author's name, publication year, country, type of coronavirus, strain/isolate, disinfectant/concentration, phase of disinfection, exposure time, reduction of viral infectivity $\left(\log _{10}\right)$, humidity, temperature, media, survival time (days), infection control strategies, and main finding was extracted.

Fig. 1 Summary of a standard four-step protocol for literature review

\section{Results}

In the present SR after the study eligibility, a total of 42 studies were identified among 86 hints which collected during the initial bibliographic search in the four international databases based on our inclusion/exclusion criteria. The details of search procedure conducted to obtained eligible studies are shown in Fig. 1. Then, all included studies were analyzed in-depth and categorized separately according to inactivation (disinfection) methods, capability to survive in different environmental conditions, and control and prevention strategies. The main results of all the 42 included studies in different parts of the study (i.e., disinfection methods, environmental survival, and control and prevention strategies) were summarized in brief in Tables 1,2, and 3, respectively.

Among all reviewed and included studies, 20 studies were categorized in the category of inactivation (disinfection) methods (Bedell et al. 2016; Dellanno et al. 2009; Eggers et al. 2015; Eggers et al. 2018; Emmoth et al. 2011; Feldmann et al. 2019; Goyal et al. 2014; Hindawi et al. 2018; Hulkower et al. 2011; Kariwa et al. 2006; Leclercq et al. 2014; Pratelli 2007; Pratelli 2008; Rabenau et al. 2005a, b; Saknimit et al. 1988; Sattar et al. 1989; Siddharta et al. 2017; Tyan et al. 2018; Wood and Payne 1998). As can be seen in Table 1, the different types of disinfection (inactivation) methods including physical and chemical types of disinfectants were presented and their efficacies were reviewed. Briefly, chemical disinfectant compounds such as ethanol, 2-propanol, and povidone iodine in different concentrations show the high efficacy in the inactivation of coronaviruses in a short time.

Among the included studies, 12 eligible studies were focused on the environmental survival of coronaviruses

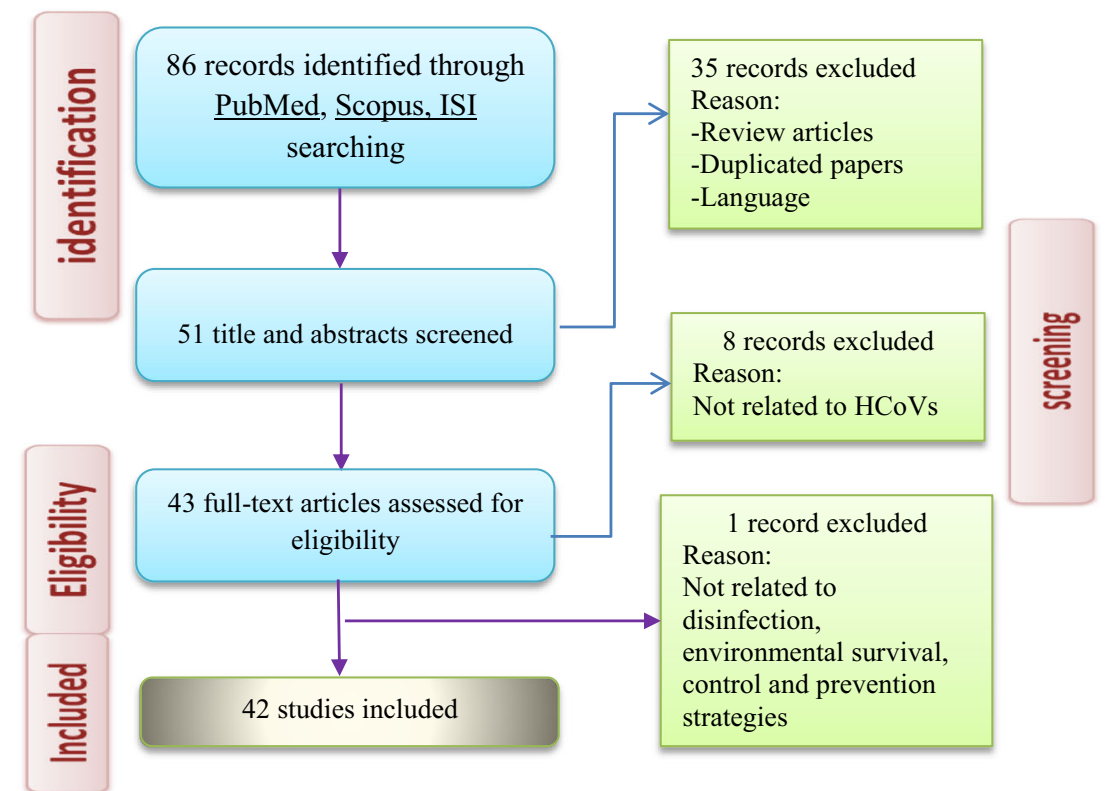




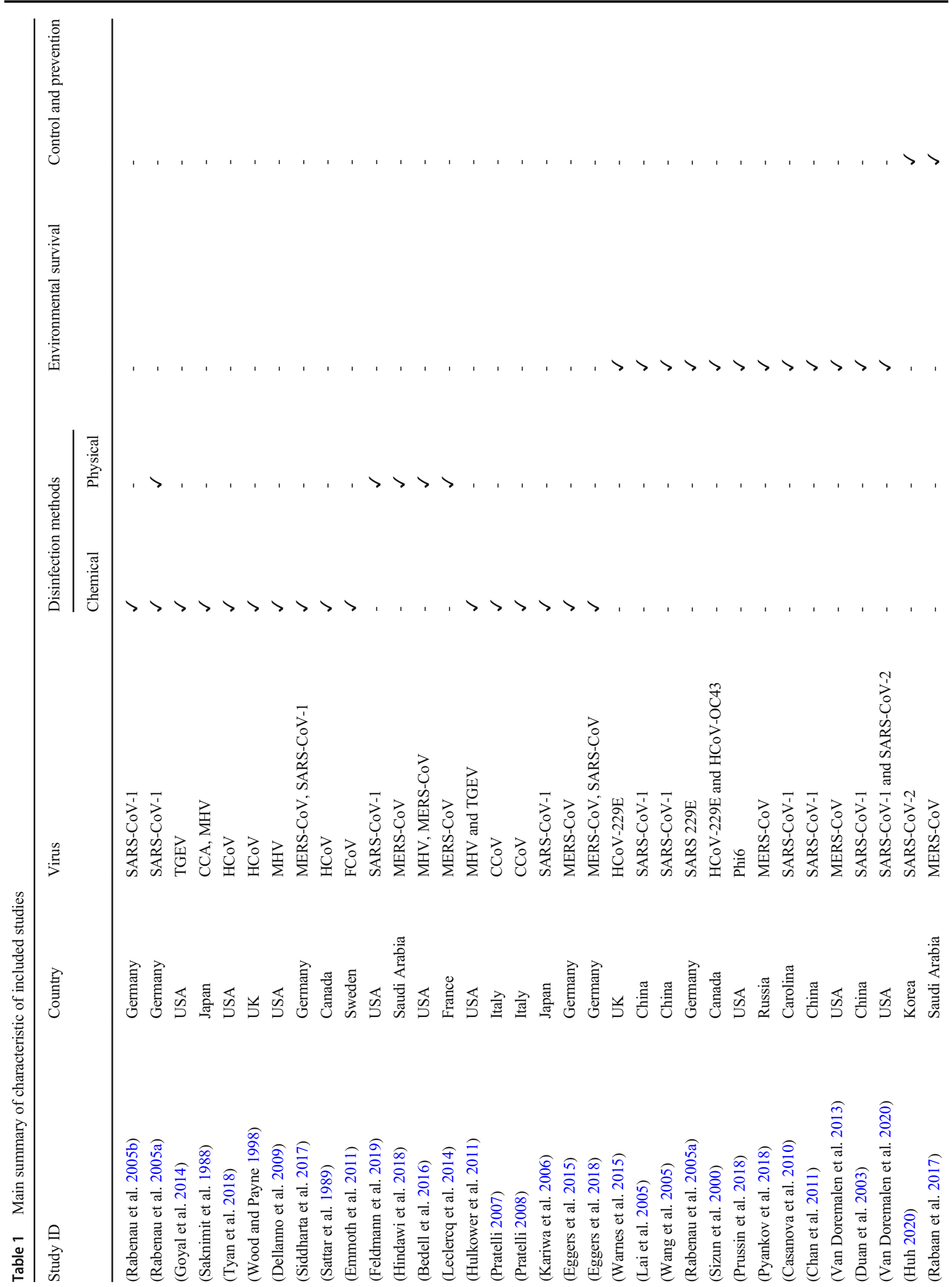


(Casanova et al. 2010; Duan et al. 2003; Sizun et al. 2000; Van Doremalen et al. 2020; Van Doremalen et al. 2013; Wang et al. 2005; Warnes et al. 2015; Chan et al. 2011; Lai et al. 2005; Prussin et al. 2018; Pyankov et al. 2018; Rabenau et al. 2005a). According to the results of the included studies in Table 2, the SARS-CoV-2 susceptibility on surfaces of different materials at $4-5{ }^{\circ} \mathrm{C}, 20-22{ }^{\circ} \mathrm{C}$, and $30-40{ }^{\circ} \mathrm{C}$ is approximately $>28$ days, $3-9$ days, and a few hours, respectively. The survival of the SARS-CoV-1 and SARS-CoV-2 in five environmental conditions (aerosols, stainless steel, plastic, cardboard, and copper) was also reported. Both viruses demonstrated survival between 3 and $72 \mathrm{~h}$ on these surfaces.

Among the included studies, 10 eligible studies were focused on the IPC of coronaviruses (Ki et al. 2019; Koul et al. 2018; Rabaan et al. 2017; Sikkema et al. 2017; El Bushra et al. 2017; Butt et al. 2016; Wiboonchutikul et al. 2016; Wong and Wai-San Tam 2005; Al-Tawfiq et al. 2019; Huh 2020). According to finding of the included studies, the SARS$\mathrm{CoV}-2$ can be easily spread via two main ways in human-tohuman transmission: (1) respiratory droplet and (2) direct and indirect contact with aerosol infected surfaces. Therefore, the main recommendations were presented in the following sections.

\section{Discussion}

The novel human coronavirus which is named as SARSCoV-2 (COVID-19) by the WHO, recently emerged from Wuhan city, China. After a short time, COVID-19 is spreading rapidly in approximately all developed and developing countries worldwide. Considering the rapid spreading and pandemic situation, the WHO assigned a global level of SARS-CoV-2 risk assessment that was very high ((WHO) 2020a, c). The officials of the WHO reported that human-tohuman transmission is the main route to spread the virus. The study reported that SARS-CoV-2 had a high stability in a favorable environment, but maybe is susceptible to the standard inactivation compounds (disinfection methods) (Chin et al. 2020). Therefore, identification of effective inactivation materials and/or disinfection methods is utmost importance. In the present up-to-date SR, we searched all the available evidence published on inactivation (disinfection) methods, and finally, 42 eligible studies were included in our study and reviewed in-depth to determine the favorable and standard disinfectants.

\section{Disinfection methods applied to inactivation of coronavirus}

Considering the results of the included studies, different chemical disinfectant compounds such as Sterillium Rub/Gel containing ethanol with different concentration $(78,80,85$, 


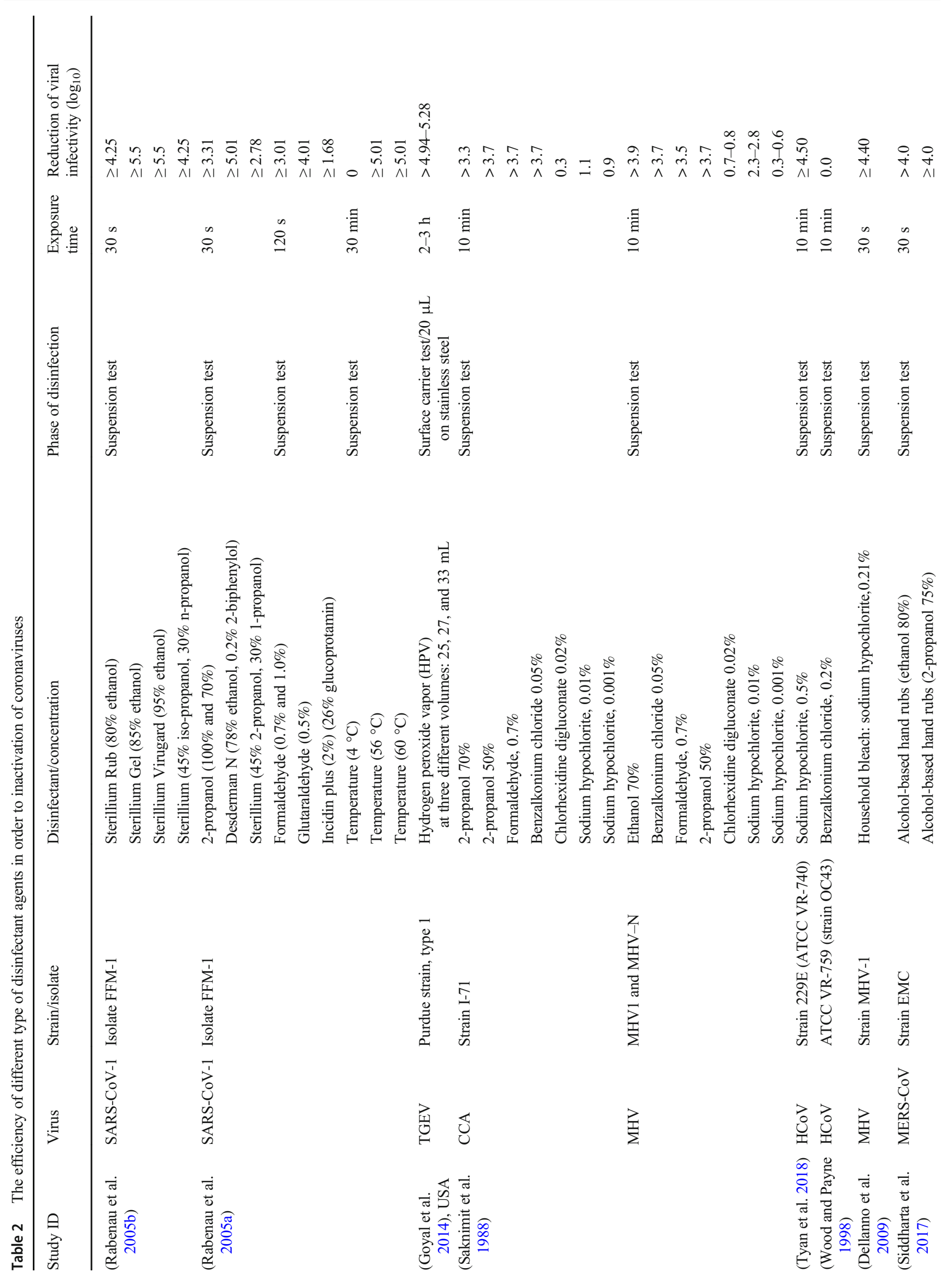




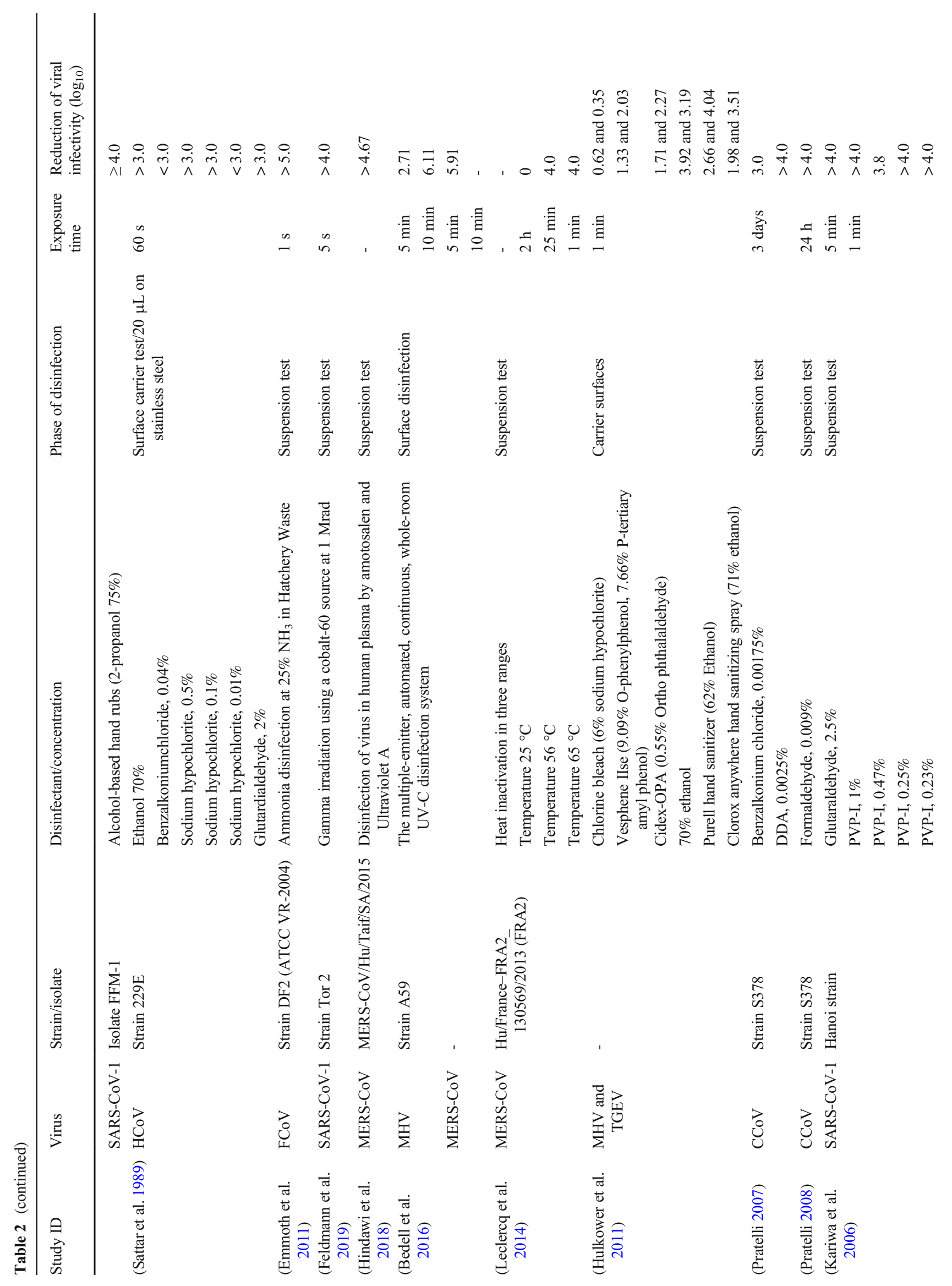




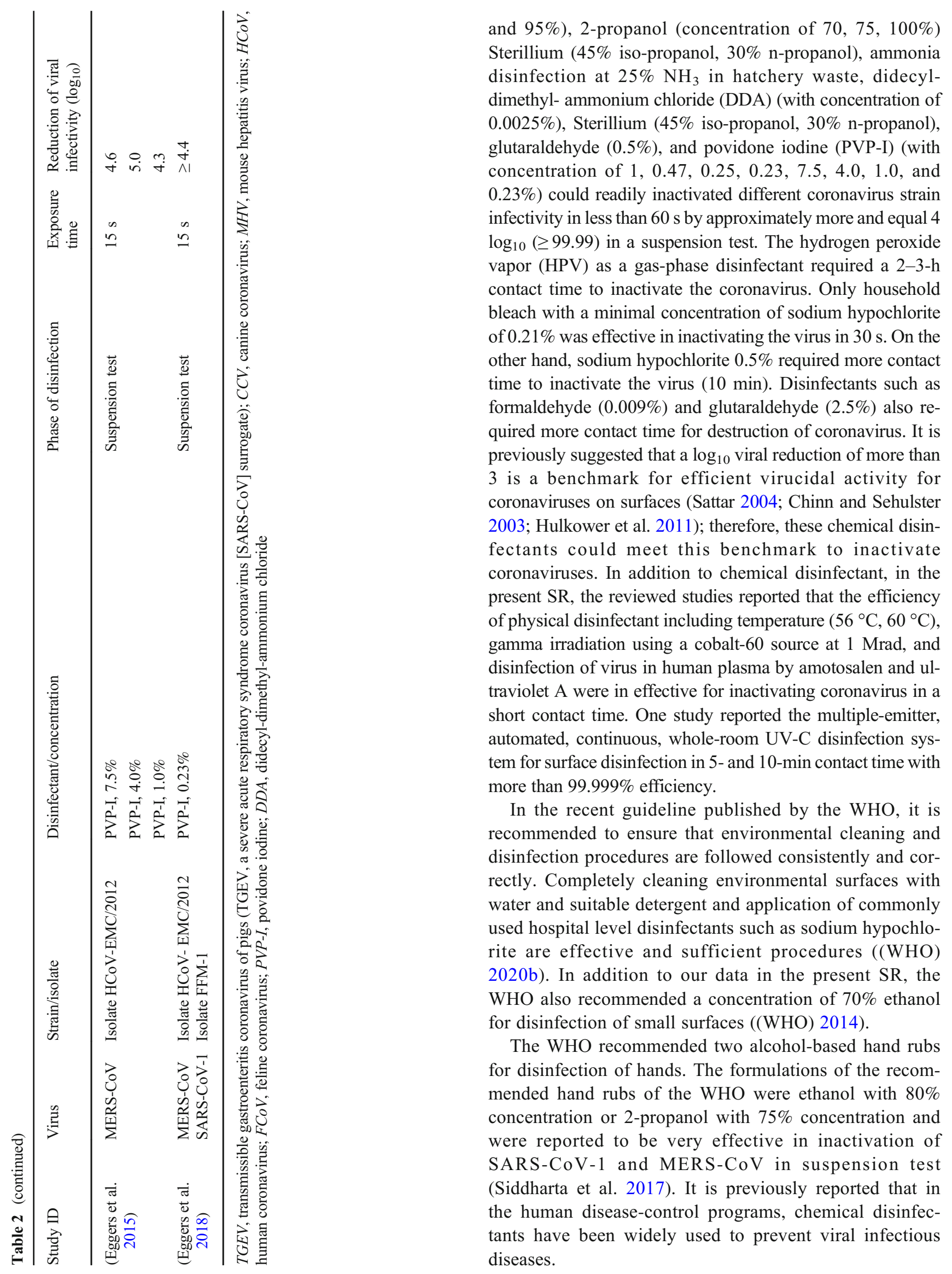




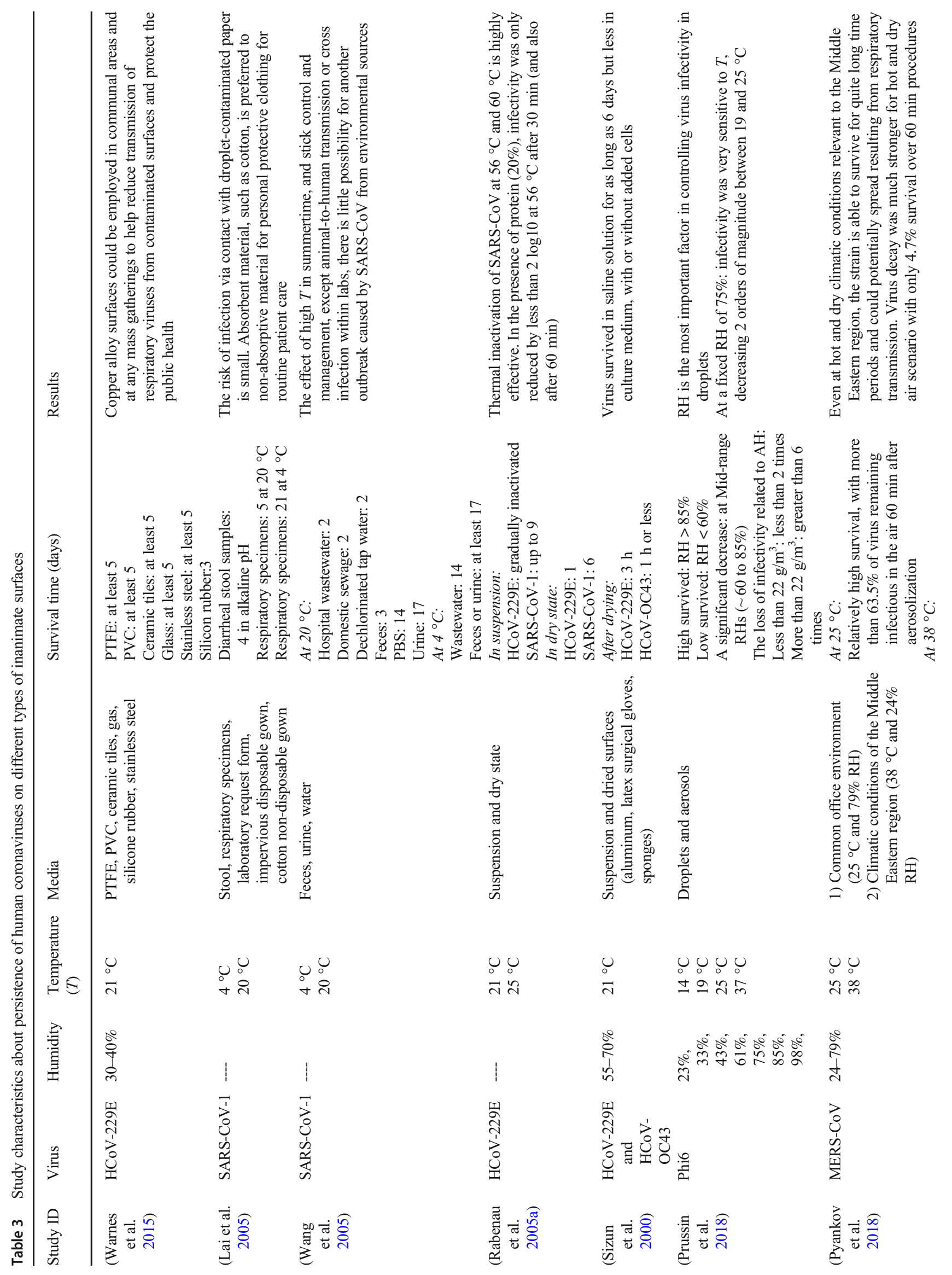




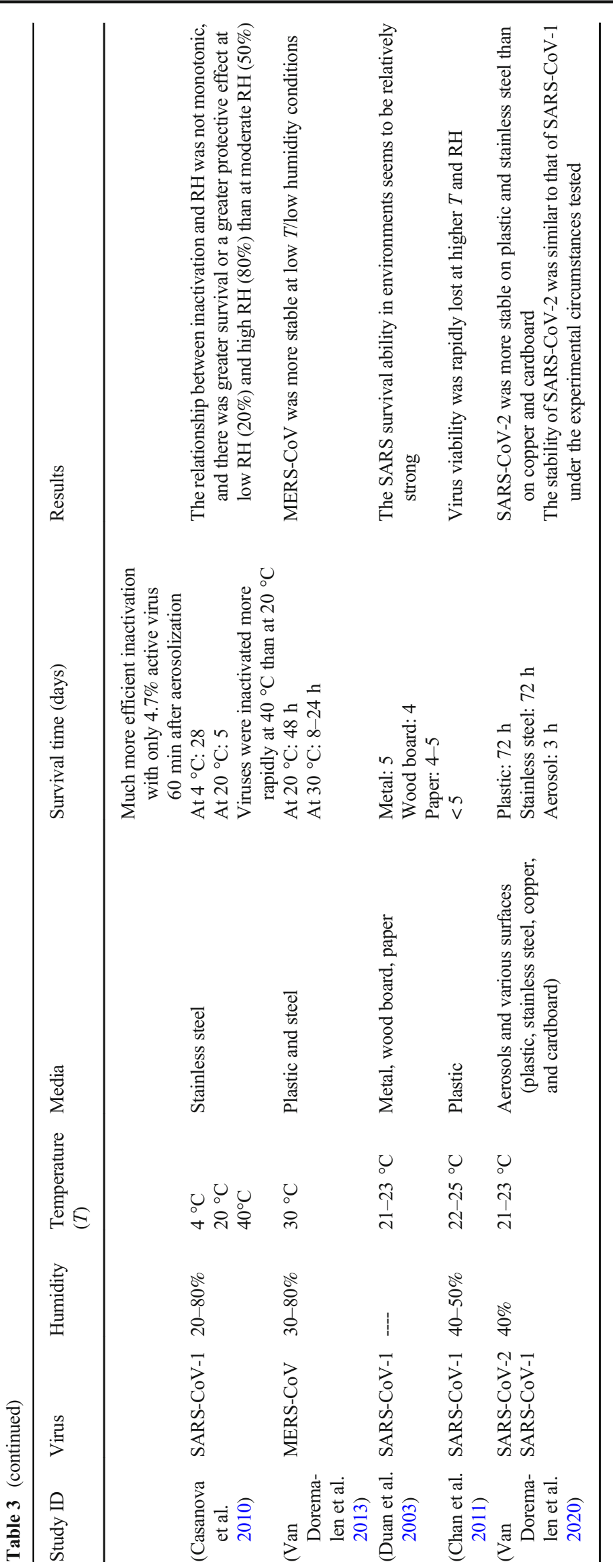




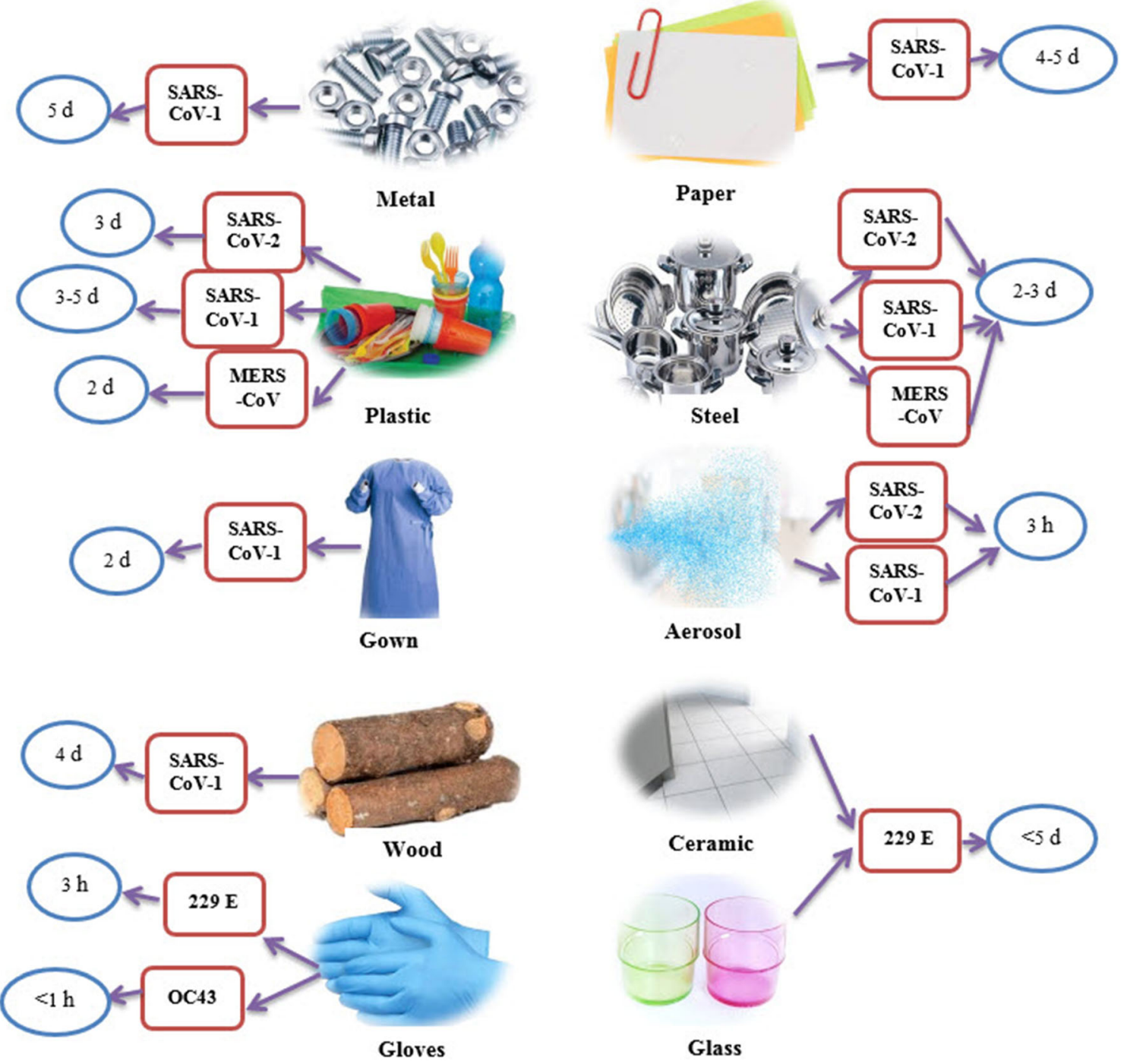

Fig. 2 Persistence of human CoVs on various surfaces according to results of included studies

\section{Survival of SARS-CoV-2 in different environmental conditions}

The present study is the first SR on SARS-CoV-2 survival on different media and control-prevention strategies. During MERS-CoV, SARS-CoV-1, and SARS-CoV-2 outbreaks, the survival time of SARS-CoV-2 on different environmental conditions is a concern for people, health-care workers, and the related-health agencies due to infection control measures. Various media including water/wastewater, air, and different surfaces in the places with high load of virus were usually contaminated to the virus by direct and indirect transmission mechanism. The main results of the reviewed studies in this SR were summarized in Table 3 .

Our study investigated the effect of different environmental parameters like temperature, absolute humidity $(\mathrm{AH})$, relative humidity $(\mathrm{RH})$, and their combinations on virus survival in various environmental conditions including droplets, aerosols, suspension and dried states, feces (stool), urine, water, wastewater, respiratory specimens, laboratory request form, aluminum, sterile latex surgical gloves, sterile sponges, impervious disposable gown, cotton non-disposable gown, polytetrafluoroethylene (Teflon; PTFE), polyvinyl chloride (PVC), ceramic tiles, gas, silicone rubber, plastic, wood, paper, cardboard, copper, and stainless steel.

On the basis of the results of included studies, virus survival in respiratory fluid droplet depends on controlling the temperature and RH. Thus, disease transmission via droplets is inhibited by increasing both temperature and $\mathrm{RH}$ in buildings like hospitals, schools, university, offices, and homes. It should be noticed that the relationship between RH, temperature, and SARS-CoV-2 inactivation especially SARS-CoV-2 is still complex, and more research is needed to know these effects on level of physiological (Rabenau et al. 2005a; Sizun et al. 2000; Prussin et al. 2018; Chin et al. 2020; Van Doremalen et al. 2013). 
Fig. 3 Summary of IPC recommendations obtained from the findings of included studies

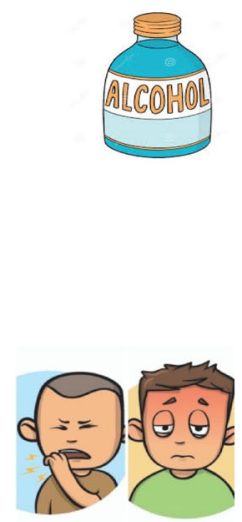

Several studies have reported that the SARS-CoV-2 susceptibility on surfaces of different materials at $4-5{ }^{\circ} \mathrm{C}, 20$ $22{ }^{\circ} \mathrm{C}$ (room temperature), and $30-40{ }^{\circ} \mathrm{C}$ is approximately $>$ 28 days, 3-9 days, and a few hours, respectively (Fig. 2). SARS-CoV-1 can survive in respiratory specimens at $20^{\circ} \mathrm{C}$ for 5 days and at $4{ }^{\circ} \mathrm{C}$ for 21 days and able to survive in diarrheal stool samples for 4 days. The reviewed results show that the SARS-CoV-2 remains infectious for several days and few hours in suspensions and after drying, respectively (Van Doremalen et al. 2013; Prussin et al. 2018; Rabenau et al. 2005a; Sizun et al. 2000; Wang et al. 2005; Warnes et al. 2015; Lai et al. 2005; Pyankov et al. 2018; Casanova et al. 2010; Chin et al. 2020; Duan et al. 2003). van Doremalen and colleagues' study was designed specifically to compare the survival of the SARS-CoV-1 and SARS-CoV-2 in five environmental conditions (aerosols, stainless steel, plastic, cardboard, and copper). Both viruses were more stable on plastic and stainless steel $(72 \mathrm{~h})$ than on copper and cardboard (4 $8 \mathrm{~h}$ ). The half-live of SARS-CoV-1 and SARS-CoV-2 were similar in aerosols (3 h) (Van Doremalen et al. 2020).

\section{Infection prevention and control recommendations}

Different reports (WHO ((WHO), W. H. O 2020d; (WHO), W. H. O 2020e), Centers for Disease Control and Prevention (CDC), governments and hospitals) and several studies
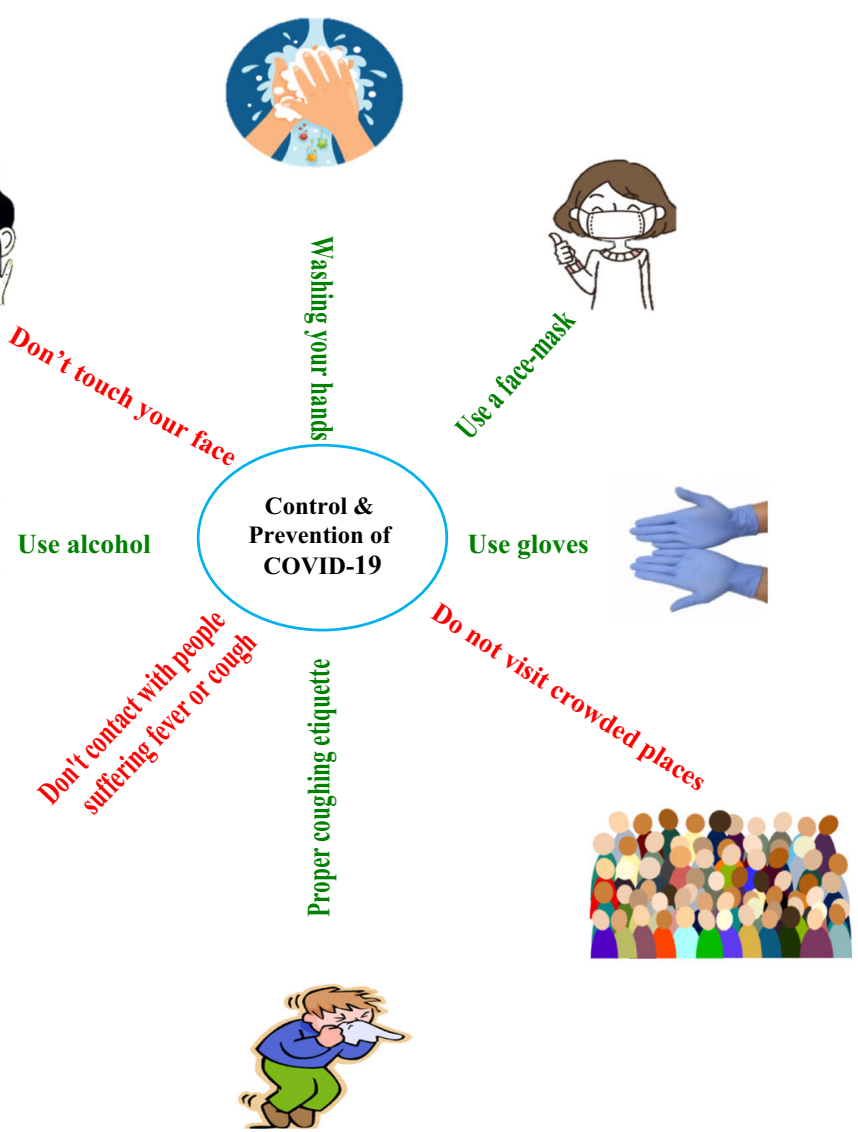

included in this SR show that SARS-CoV-2 can be easily spread via two main ways in human-to-human transmission: (1) respiratory droplet and (2) direct and indirect contact with aerosol-infected surfaces. These databases are recommended guidelines for IPC for emergency responses to outbreaks of respiratory viruses. Recommended strategies play an essential role in preventing the infection transmission (Ki et al. 2019, Koul et al. 2018, Butt et al. 2016, Rabaan et al. 2017, Sikkema et al. 2017, El Bushra et al. 2017, (WHO) 2014, 2020a, AlTawfiq et al. 2019, Wong and Wai-San Tam 2005, Wiboonchutikul et al. 2016, (CDC) 2020, Huh 2020). Some of the most important recommendations to consider for IPC include the following (Fig. 3):

- Maintaining social distance (1-1.5 m) between people in indoor "red zones"

- The use of alcohol-based disinfectant (adequate hand hygiene) or hot water and soap for cleaning hands for $30 \mathrm{~s}$ or longer after contact with infected person fluids and before eating

- The use of disposable gloves, shoe cover, and longsleeved gowns in contact with the infected person's body fluids or feces

- The use of surgical/N95 masks, eyeglasses, and face shield for covering the mouth, the nose, the eye, and the face in confronting with a person with SARS-CoV-2 in the same room 
- Do not touch the face (mouth, eyes, or nose) with your hands

- Appropriate coughing or sneezing etiquette (respiratory hygiene) with a tissue, medical mask, or flexed elbow or a sleeve

- Do not eat or drink in the ward

- The use of disposable or plastic covers for inanimate objects like keyboard, pens, and pagers

- The use of alcohol-based detergents for cleaning of equipment and different surfaces

- Take a shower immediately when direct contact with infected person fluids or respiratory droplets

- The isolation of persons (the use of separate room) with specific diagnosis for at least 14 days until the symptoms of the disease (fever, coughing, or sneezing) are over

- Health education via different methods of communication

- Vaccination

- Management of health-care worker exposures

- Do not visit crowded places

- Proper ventilation of the buildings in time of aerosol generating

- Try to minimize work time and stay at home until end outbreak

- Avoid being exposed to the SARS-CoV-2 virus is the best way to prevent illness

\section{Conclusions}

The results of the present SR reveal that SARS-CoV-2 can survive in the range of a few hours up to 28 days in the different environmental conditions depending on the temperature and relative humidity. The results of reviewed studies confirmed that two alcohol-based hand rub formulations recommended by the WHO (such as ethanol with $78,80,85$, and $95 \%$ concentration and 2-propanol with concentration of 70,75 , and $100 \%$ ) had an efficient virucidal activity in less than 60 s by approximately $\geq 4 \log _{10}(\geq 99.99)$ in suspension test and could be used for disinfecting the public health and health-care facilities. The main virus transmission routes are human-to-human transmission, spreads via respiratory droplets, and contaminated hands or surfaces. We hope that the results of the present SR can help to researchers, health decision-makers, policy-makers, and people for having the proper behavior to control and prevent further spread of SARS-CoV-2.

Funding The present study was supported by the Ilam University of Medical Sciences (IUMS) (grant no.: IR.MEDILAM.REC.1399.042) financially.

\section{Compliance with ethical standards}

Competing interests The authors declare that they have no competing interests.

\section{References}

(CDC), C. F. D. C. A. P. (2020) How to protect yourself and others

(WHO), W. H. O. (2020a) Coronavirus disease (COVID-19), situation report -102

(WHO), W. H. O. (2020b) Coronavirus disease 2019 (COVID-19) situation report -95

(WHO), W. H. O. (2014) Infection prevention and control of epidemicand pandemic-prone acute respiratory infections in health care, World Health Organization

(WHO), W. H. O. (2020c) Infection prevention and control during health care when novel coronavirus ( $\mathrm{nCoV}$ ) infection is suspected: interim guidance, January 2020. World Health Organization

(WHO), W. H. O. (2020d) Infection prevention and control during health care when novel coronavirus $(\mathrm{nCoV})$ infection is suspected interim guidance, 19 March 2020

(WHO), W. H. O. (2020e) Water, sanitation, hygiene, and waste management for the COVID-19 virus: interim guidance, 23 April 2020. World Health Organization

Abreu AC, Tavares RR, Borges A, Mergulhão F, Simões M (2013) Current and emergent strategies for disinfection of hospital environments. J Antimicrob Chemother 68:2718-2732

Al-Rabiaah A, Temsah M-H, Al-Eyadhy AA, Hasan GM, Al-Zamil F, Al-Subaie S, Alsohime F, Jamal A, Alhaboob A, Al-Saadi B (2020) Middle East Respiratory Syndrome-Corona Virus (MERS-CoV) associated stress among medical students at a university teaching hospital in Saudi Arabia. J Infect Public Health

Al-Tawfiq JA, Abdrabalnabi R, Taher A, Mathew S, Rahman KA (2019) Infection control influence of Middle East respiratory syndrome coronavirus: a hospital-based analysis. Am J Infect Control 47: 431-434

Bedell K, Buchaklian AH, Perlman S (2016) Efficacy of an automated multiple emitter whole-room ultraviolet-C disinfection system against coronaviruses MHV and MERS-CoV. Infect Control Hosp Epidemiol 37:598-599

Butt TS, Koutlakis-Barron I, Aljumaah S, Althawadi S, Almofada S (2016) Infection control and prevention practices implemented to reduce transmission risk of Middle East respiratory syndromecoronavirus in a tertiary care institution in Saudi Arabia. Am J Infect Control 44:605-611

Carling P, Von Beheren S, Kim P, Woods C (2008) Intensive care unit environmental cleaning: an evaluation in sixteen hospitals using a novel assessment tool. J Hosp Infect 68:39-44

Casanova LM, Jeon S, Rutala WA, Weber DJ, Sobsey MD (2010) Effects of air temperature and relative humidity on coronavirus survival on surfaces. Appl Environ Microbiol 76:2712-2717

Chan K, Peiris J, Lam S, Poon L, Yuen K, Seto W (2011) The effects of temperature and relative humidity on the viability of the SARS coronavirus. Adv Virol 2011:1-7

Chang L, Yan Y, Wang L (2020) Coronavirus disease 2019: coronaviruses and blood safety. Transfus Med Rev 34:75-80

Chin A, Chu J, Perera M, Hui K, Yen H-L, Chan M, Peiris M, Poon L (2020) Stability of SARS-CoV-2 in different environmental conditions. medRxiv

Chinn RY, Sehulster L (2003) Guidelines for environmental infection control in health-care facilities; recommendations of CDC and Healthcare Infection Control Practices Advisory Committee (HICPAC) 
Dellanno C, Vega Q, Boesenberg D (2009) The antiviral action of common household disinfectants and antiseptics against murine hepatitis virus, a potential surrogate for SARS coronavirus. Am J Infect Control 37:649-652

Ding Y, Wang H, Shen H, Li Z, Geng J, Han H, Cai J, Li X, Kang W, Weng D (2003) The clinical pathology of severe acute respiratory syndrome (SARS): a report from China. J Pathol 200:282-289

Duan S, Zhao X, Wen R, Huang J-J, Pi G, Zhang S, Han J, Bi S, Ruan L, Dong X-P (2003) Stability of SARS coronavirus in human specimens and environment and its sensitivity to heating and UV irradiation. Biomed Environ Sci 16:246-255

Eggers M, Eickmann M, Zorn J (2015) Rapid and effective virucidal activity of povidone-iodine products against Middle East respiratory syndrome coronavirus (MERS-CoV) and modified vaccinia virus Ankara (MVA). Infect Dis Ther 4:491-501

Eggers M, Koburger-Janssen T, Eickmann M, Zorn J (2018) In vitro bactericidal and virucidal efficacy of povidone-iodine gargle/ mouthwash against respiratory and oral tract pathogens. Infect Dis Ther 7:249-259

El Bushra HE, Al Arbash HA, Mohammed M, Abdalla O, Abdallah MN, Al-Mayahi ZK, Assiri AM, Binsaeed AA (2017) Outcome of strict implementation of infection prevention control measures during an outbreak of Middle East respiratory syndrome. Am J Infect Control 45:502-507

Emmoth E, Ottoson J, Albihn A, Belák S, Vinnerås B (2011) Ammonia disinfection of hatchery waste for elimination of single-stranded RNA viruses. Appl Environ Microbiol 77:3960-3966

Feldmann F, Shupert WL, Haddock E, Twardoski B, Feldmann H (2019) Gamma irradiation as an effective method for inactivation of emerging viral pathogens. Am J Trop Med Hygiene 100:1275-1277

Goyal SM, Chander Y, Yezli S, Otter J (2014) Evaluating the virucidal efficacy of hydrogen peroxide vapour. J Hosp Infect 86:255-259

Hindawi SI, Hashem AM, Damanhouri GA, El-Kafrawy SA, Tolah AM, Hassan AM, Azhar EI (2018) Inactivation of Middle East respiratory syndrome-coronavirus in human plasma using amotosalen and ultraviolet A light. Transfusion 58:52-59

Huh S (2020) How to train health personnel to protect themselves from SARS-CoV-2 (novel coronavirus) infection when caring for a patient or suspected case. J Educ Evaluat Health Profess 17

Hulkower RL, Casanova LM, Rutala WA, Weber DJ, Sobsey MD (2011) Inactivation of surrogate coronaviruses on hard surfaces by health care germicides. Am J Infect Control 39:401-407

Kariwa H, Fujii N, Takashima I (2006) Inactivation of SARS coronavirus by means of povidone-iodine, physical conditions and chemical reagents. Dermatology 212(suppl 1):119-123

Ki HK, Han SK, Son JS, Park SO (2019) Risk of transmission via medical employees and importance of routine infection-prevention policy in a nosocomial outbreak of Middle East respiratory syndrome (MERS): a descriptive analysis from a tertiary care hospital in South Korea. BMC Pulmonary Med 19:190

Koul PA, Mir H, Saha S, Chadha MS, Potdar V, Widdowson M-A, Lal RB, Krishnan A (2018) Respiratory viruses in returning Hajj \& Umrah pilgrims with acute respiratory illness in 2014-2015. Indian J Med Res 148:329-333

Lai MY, Cheng PK, Lim WW (2005) Survival of severe acute respiratory syndrome coronavirus. Clin Infect Dis 41:e67-e 71

Leclercq I, Batejat C, Burguière AM, Manuguerra JC (2014) Heat inactivation of the $\mathrm{M}$ iddle $\mathrm{E}$ ast respiratory syndrome coronavirus. Influenza Other Respir Viruses 8:585-586

Mohamoud YA, Mumtaz GR, Riome S, Miller DW, Abu-Raddad LJ (2013) The epidemiology of hepatitis C virus in Egypt: a systematic review and data synthesis. BMC Infectious Diseases 13:288. https:// doi.org/10.1186/1471-2334-13-288

Noorimotlagh Z, Seyyed AM, Susana SM, Dominik R, Mehran H, Neemat J (2020) Environmental Exposure to Nonylphenol and
Cancer Progression Risk-a Systematic Review. Environ Res 184: 109263. https://doi.org/10.1016/j.envres.2020.109263

Peng PW, Ho P-L, Hota SS (2020) Outbreak of a new coronavirus: what anaesthetists should know. Br J Anaesth 124:497-501

Pitten F-A, Werner H-P, Kramer A (2003) A standardized test to assess the impact of different organic challenges on the antimicrobial activity of antiseptics. J Hosp Infect 55:108-115

Pratelli A (2007) Action of disinfectants on canine coronavirus replication in vitro. Zoonoses Public Health 54:383-386

Pratelli A (2008) Canine coronavirus inactivation with physical and chemical agents. Vet J 177:71-79

Prussin AJ, Schwake DO, Lin K, Gallagher DL, Buttling L, Marr LC (2018) Survival of the enveloped virus Phi6 in droplets as a function of relative humidity, absolute humidity, and temperature. Appl Environ Microbiol 84:e00551-e00518

Pyankov OV, Bodnev SA, Pyankova OG, Agranovski IE (2018) Survival of aerosolized coronavirus in the ambient air. J Aerosol Sci 115: $158-163$

Rabaan AA, Alhani HM, Bazzi AM, Al-Ahmed SH (2017) Questionnaire-based analysis of infection prevention and control in healthcare facilities in Saudi Arabia in regards to Middle East Respiratory Syndrome. J Infect Public Health 10:548-563

Rabenau H, Cinatl J, Morgenstern B, Bauer G, Preiser W, Doerr H (2005a) Stability and inactivation of SARS coronavirus. Med Microbiol Immunol 194:1-6

Rabenau H, Kampf G, Cinatl J, Doerr H (2005b) Efficacy of various disinfectants against SARS coronavirus. J Hosp Infect 61:107-111

Saknimit M, Inatsuki I, Sugiyama Y, Yagami K-I (1988) Virucidal efficacy of physico-chemical treatments against coronaviruses and parvoviruses of laboratory animals. Exp Anim 37:341-345

Sattar S (2004) Microbicides and the environmental control of nosocomial viral infections. J Hosp Infect 56:64-69

Sattar S, Springthorpe V, Karim Y, Loro P (1989) Chemical disinfection of non-porous inanimate surfaces experimentally contaminated with four human pathogenic viruses. Epidemiol Infect 102:493-505

Siddharta A, Pfaender S, Vielle NJ, Dijkman R, Friesland M, Becker B, Yang J, Engelmann M, Todt D, Windisch MP (2017) Virucidal activity of World Health Organization-recommended formulations against enveloped viruses, including zika, ebola, and emerging coronaviruses. J Infect Dis 215:902-906

Sikkema RS, Farag EA, Himatt S, Ibrahim AK, Al-Romaihi H, Al-Marri SA, Al-Thani M, El-Sayed AM, Al-Hajri M, Haagmans BL (2017) Risk factors for primary Middle East respiratory syndrome coronavirus infection in camel workers in Qatar during 2013-2014: a casecontrol study. J Infect Dis 215:1702-1705

Singhal T (2020) A review of coronavirus disease-2019 (COVID-19). Indian J Pediatr:1-6

Sizun J, Yu M, Talbot P (2000) Survival of human coronaviruses 229E and OC43 in suspension and after drying on surfaces: a possible source of hospital-acquired infections. J Hosp Infect 46:55-60

Smatti MK, Al Thani AA, Yassine HM (2018) Viral-induced enhanced disease illness. Front Microbiol 9:2991

Sohrabi C, Alsafi Z, O'neill N, Khan M, Kerwan A, Al-Jabir A, Iosifidis C, Agha R (2020) World Health Organization declares global emergency: a review of the 2019 novel coronavirus (COVID-19). Int J Surg

Tyan K, Kang J, Jin K, Kyle AM (2018) Evaluation of the antimicrobial efficacy and skin safety of a novel color additive in combination with chlorine disinfectants. Am J Infect Control 46:1254-1261

Van Doremalen N, Bushmaker T, Morris DH, Holbrook MG, Gamble A, Williamson BN, Tamin A, Harcourt JL, Thornburg NJ, Gerber SI (2020) Aerosol and surface stability of SARS-CoV-2 as compared with SARS-CoV-1. N Engl J Med 382:1564-1567

Van Doremalen N, Bushmaker T, Munster V (2013) Stability of Middle East respiratory syndrome coronavirus (MERS-CoV) under different environmental conditions. Eurosurveillance 18:20590 
Wang X-W, Li J-S, Jin M, Zhen B, Kong Q-X, Song N, Xiao W-J, Yin J, Wei W, Wang G-J (2005) Study on the resistance of severe acute respiratory syndrome-associated coronavirus. J Virol Methods 126: $171-177$

Warnes SL, Little ZR, Keevil CW (2015) Human coronavirus 229E remains infectious on common touch surface materials. MBio 6: e01697-e01615

Wiboonchutikul S, Manosuthi W, Likanonsakul S, Sangsajja C, Kongsanan P, Nitiyanontakij R, Thientong V, Lerdsamran H, Puthavathana P (2016) Lack of transmission among healthcare workers in contact with a case of Middle East respiratory syndrome coronavirus infection in Thailand. Antimicrob Resist Infect Control 5:21
Wong T-W, Wai-San Tam W (2005) Handwashing practice and the use of personal protective equipment among medical students after the SARS epidemic in Hong Kong. Am J Infect Control 33:580-586

Wood A, Payne D (1998) The action of three antiseptics/disinfectants against enveloped and non-enveloped viruses. J Hosp Infect 38: 283-295

Yin Y, Wunderink RG (2018) MERS, SARS and other coronaviruses as causes of pneumonia. Respirology 23:130-137

Publisher's note Springer Nature remains neutral with regard to jurisdictional claims in published maps and institutional affiliations.

\section{Affiliations}

\section{Zahra Noorimotlagh $^{1,2} \cdot$ Seyyed Abbas Mirzaee ${ }^{1,2}($ D $)$ Neemat Jaafarzadeh $^{3} \cdot$ Maryam Maleki $^{4} \cdot$ Gholamreza Kalvandi ${ }^{5}$. Chiman Karami ${ }^{6}$}

1 Zoonotic Diseases Research Center, Ilam University of Medical Sciences, Ilam, Iran

2 Department of Environmental Health Engineering, Faculty of Health, Ilam University of Medical Sciences, Ilam, Iran

3 Environmental Technologies Research Center, Ahvaz Jundishapur University of Medical Sciences, Ahvaz, Iran
4 Department of Physiology, Faculty of Medicine, Ilam University of Medical Sciences, Ilam, Iran

5 Department of Pediatrics Gastroenterology, School of Medicine, Ilam University of Medical sciences, Ilam, Iran

6 Department of Microbiology, Parasitology and Immunology, Ardabil University of Medical Sciences, Ardebil, Iran 